\title{
In vitro UV absorption properties and radical scavenging capacity of Morella parvifolia (Benth.) Parra-Os. extracts
}

\author{
Miguel Angel Puertas-Mejía ${ }^{*}$, María Isabel Gutierrez-Villegas', Juan Camilo Mejía-Giraldo, \\ Robert Winkler², Benjamín Rojano ${ }^{3}$
}

\begin{abstract}
${ }^{1}$ Research Group on Functional Compounds, Institute of Chemistry, University of Antioquia, Medellin, Colombia, ${ }^{2}$ Department of Biotechnology and Biochemistry, CINVESTAV Unidad Irapuato, Irapuato-León, Irapuato Gto., Mexico, ${ }^{3}$ Food Science Laboratory, Chemistry School, Universidad Nacional de Colombia, Medellín, Colombia
\end{abstract}

\begin{abstract}
The goal of this research was to identify major compounds of the aerial parts of M. parvifolia (Benth.) Parra-Os., that could enhance its possible application as additive in dermocosmetic products, as well as evaluate the antioxidant properties. The extracts agreed with the broad-spectrum UVB/UVA absorption detected and could act as broad-spectrum sunscreens, covering the UVA and UVB range. Methanolic extracts showed an important antiradical capacity $(0.46$ and $0.47 \mathrm{~g} / \mu \mathrm{mol} \mathrm{DPPH}), \mathrm{TPC}(37.58$ and $51.41 \mathrm{mg}$ GAE/g DS) and TAC (1.12 and $3.31 \mathrm{mg} \mathrm{C} 3 \mathrm{GE} / \mathrm{g}$ DS) in fruits and leaves, respectively. M. parvifolia could be considered as a prospective source of natural UV-radiation absorbers with antioxidant capacity. Although the results have clearly demonstrated the potential photoprotection capacity, more studies are needed to enhance its application as an additive in pharmaceutical and medicinal formulations.
\end{abstract}

Keywords: Morella parvifolia. Potential skin barrier. UV absorption capacity. Pharmaceutical additive.

\section{INTRODUCTION}

Natural bioactive compounds isolated from plants may act as potential antioxidant, antimutagenic, antiinflammatory and anticarcinogenic agents to reduce the UV generated ROS-mediated photodamage, immunesuppression and skin cancer in patients (Katiyar et al., 1999; 2000; Stahl et al., 2000; Zhou et al., 2009b; Morales et al., 2011). In that line, bioactive compounds such as vitamin $C$, vitamin $E$ and carotenoids, phenolic acids, catechins, flavonols and anthocyanins have shown strong antioxidant activity, and all of them can be used as bio-additives in medicinal, food and dermocosmetic products (F'guyer, Afaq, Mukhtar, 2003; Duraisamy et al., 2011; Jarzycka et al., 2013) on account of their beneficial health effects. For a long time, plants have been used for their ethno-botanical and ethno-pharmacological relevance. However, at present day, many of them are not supported by adequate scientific reports about their potential industrial applications. For instance, information

\footnotetext{
*Correspondence: M. Puertas-Mejía. Research Group on Functional Compounds, Institute of Chemistry, University of Antioquia, Calle 70 No. 52-21, Apartado Aéreo 1226, Medellín, Colombia.E-mail: miguel.puertas@udea.edu.co
}

about chemical and biological properties of vegetation from ecosystems over 2000 meters above sea level is scarce. These plants are exposed to hard environmental conditions, which induce them to synthetize metabolites as natural defences against oxidative stress due to high levels of ultraviolet radiation, low temperature etc. (Crockett et al., 2010). The most common compounds found in these plants are polyphenols that have demonstrated antioxidant activity. Also, it has been observed that some of them are capable of absorbing UV radiation (Agati, Tattini, 2010; Agati et al., 2013).

Considering the increased exposition to solar UV radiation and the potential risk for human beings, research on new natural sources with high content of chemical compounds able to absorb ultraviolet radiation have become a hot topic in recent years (Jarzycka et al., 2013; PérezSánchez et al., 2014). Morella parvifolia (Benth.) Parra-Os., a shrub that belongs to the Myricaceae family and can be found in Colombia, Venezuela, Ecuador and Perú between 1300 to 3800 meters above sea level, is exposed to adverse environmental conditions such as fluctuations of rainfall and temperature, high humidity, low temperature and high UV radiation (Parra, 2003; Gonzales de la Cruz et al., 2014). These exceptional conditions induce the plants to produce 
bioactive compounds such as phenolic acids, flavonoids and high molecular weight polyphenols; all of them are natural defences against those ecological factors that are involved in UV generated ROS-mediated photodamage, immune-suppression and skin cancer (Bieza, Lois, 2001; Svobodová, Psotová, Walterová, 2003; Mellegård et al., 2009). On the other hand, erythema caused by solar radiation is the best-known acute effect of prolonged human exposure to UV radiation. This electromagnetic radiation induces degenerative changes in skin cells, resulting in premature skin aging (Damiani et al., 2006; Ponzo, Silvia, 2013). Furthermore, some species of Myricaceae have been used in the treatment of chest-related diseases, painful menstruation, and to enhance men's sexual performance (Ashafa, 2015). In addition, the anticancer capacity against human lung cell carcinoma was reported in extracts of Myrica gale L. (Sylvestre et al., 2005). According to our information, studies on photoprotection and UV absorption potential of $M$. parvifolia have not yet been reported. Therefore, the aim of this study was to evaluate specifically the phytochemistry and biological activities of M. parvifolia grown in the Andean Mountains of Antioquia-Colombia, with regard to their in vitro UV-radiation absorption capacity, main phenolic compounds and antioxidant capacity, in order to propose it as non-conventional source of skin-care additives.

\section{MATERIAL AND METHODS}

\section{Plant materials, chemicals, extraction and phytochemical analysis}

Fresh vegetal material, leaves and fruits (mature stage) of M. parvifolia (Benth.) Parra-Os. were collected in March 2013 during rainy season and flowering stage, at Llanos de Cuivá, Santa Rosa de Osos, Antioquia, Colombia at 2700 meter above sea level (Geographical coordinates: $\left.6^{\circ} 49^{\prime} 50.6^{\prime \prime} \mathrm{N} ; 7^{\circ} 29^{\prime} 29.9^{\prime \prime} \mathrm{W}\right)$. A voucher specimen was deposited in the Herbarium of the University of Antioquia (HUA) under registry code HUA192390.

2,2-Diphenyl-2-picrylhydrazyl (DPPH) stable radical, gallic acid, rutin, benzophenone 3 (B3), butyl methoxydibenzoylmethane, (BMDM) and ethylhexyl methoxycinnamate (EHMC) were obtained from Sigma Chemical Co. (St. Louis, MO). Myricetin-3-glucoside, myricetin-3-rhamnoside and cyanidin-3-rutinoside were purchased from Extrasynthese (Lyon, France). FolinCiocalteu phenol reagent, methanol, ethanol, hydrochloric acid $37 \%$, potassium chloride, sodium acetate and sodium carbonate were obtained from Merck Chemical Supplies (Damstadt, Germany). Formic acid was obtained from
Fermont (Monterrey, NL, México). 2-thiobarbituric acid (TBA), butylated hydroxyl toluene (BHT) and methyl linoleate (MeLo) were purchased from Alfa Aesar (Ward Hill, MA).

All fresh vegetal material was processed in March 2013. Leaves and fruits were dried at room temperature, protected from sun and artificial light for one week. Then, the dry sample (DS) was crushed using an electric grinder (IKA, A11 basic S1). Next, dry and powdered leaves or fruits of M. parvifolia (c.a. $1.0 \mathrm{~g}$ ) were mixed with $50 \mathrm{~mL}$ methanol and $0.5 \mathrm{~mL} \mathrm{HCl}(37 \%, \mathrm{v} / \mathrm{v})$ for $24 \mathrm{~h}$ at room temperature and magnetically stirred at $900 \mathrm{rpm}$. The resultant solution, previously filtered, was evaporated to dryness in a rotary-evaporator under reduced pressure at 40 ${ }^{\circ} \mathrm{C}$. Then, extracts were redissolved in methanol and keep at $4{ }^{\circ} \mathrm{C}$ before analysis. The content of phytochemicals such as phenols, flavonoids, anthocyanins, quinones, and tannins was analysed using dry material dissolved in ethanol:water (1:1) according to methods described by Dohou (Dohou et al., 2003).

\section{Total polyphenol content (TPC)}

The total polyphenol content in leaves and fruits extracts was determined using the Folin-Ciocalteu colorimetric technique with some modifications (MejíaGiraldo et al., 2016). Briefly, leaf and fruit extract solutions (c.a. $0.1 \mathrm{~mL}$ ) were added to $0.125 \mathrm{~mL}$ of the Folin-Ciocalteu reagent and $1.25 \mathrm{~mL}$ of $20 \%(\mathrm{w} / \mathrm{v})$ $\mathrm{Na}_{2} \mathrm{CO}_{3}$. After incubation for $90 \mathrm{~min}$ at room temperature, the absorbance was read at $760 \mathrm{~nm}$ using an Evolution $60 \mathrm{~S}$ spectrophotometer (Thermo Fisher Scientific, Inc., Shanghai, China). The results were expressed as gallic acid equivalents per gram of dry extract (GAE/g DS).

\section{Total anthocyanin content (TAC)}

Total anthocyanins were estimated by a $\mathrm{pH}$ differential method (Lee, Durst, Wrolstad, 2005) with some modifications. An aliquot (c.a. $1.0 \mathrm{~mL}$ ) of solution of extract was mixed with $2 \mathrm{~mL}$ of buffer at $\mathrm{pH} 1.0$ (hydrochloric acid/potassium chloride; $0.025 \mathrm{M}$ ) and another at $\mathrm{pH} 4.5$ (acetic acid/sodium acetate; $0.4 \mathrm{M}$ ). After that, absorbance (A) was measured in a Thermo Scientific Evolution 60S UV-Visible spectrophotometer at 510 and $700 \mathrm{~nm}$. The anthocyanin pigment concentration was expressed as cyanidin-3-O-glucoside equivalents using the following equation:

Total Anthocyanin Content $(\mathrm{TAC}, \mathrm{mg} / \mathrm{L})=$ $(A \times M W \times D F \times 1000) /(\varepsilon \times 1)$ 
where $\mathrm{A}=$ absorbance $=\left(\mathrm{A}_{520 \mathrm{~nm}}-\mathrm{A}_{700 \mathrm{~nm}}\right)_{\mathrm{pH} 1.0}-\left(\mathrm{A}_{520 \mathrm{~nm}}-\right.$ $\left.\mathrm{A}_{700 \mathrm{~nm}}\right)_{\mathrm{pH} .5}$; $\mathrm{MW}$ is the molecular weight for cyanidin-3$O$-glucoside $($ cyd-3-glu $)=449.2 \mathrm{~g} / \mathrm{mol}$; DF is the dilution factor established; 1 is the path length of the cell in $\mathrm{cm} ; \varepsilon$ is the molar extinction coefficient of cyd-3-glu $=26900$ $\mathrm{L} / \mathrm{mol} \mathrm{cm}$; and $10^{+3}$ is the conversion factor.

\section{In vitro DPPH radical assay}

This technique is based on the reduction of the DPPH radical (purple-coloured) into the corresponding yellow hydrazine (DPPH-H) by the antioxidant (H-transfer reaction) (Pereira, Tavano, 2014). The radical scavenging capacity of each extract in different concentrations was estimated according to the method described previously (Brand-Williams, Cuvelier, Berset, 1995) with some modifications; the effective relative concentration $\left(\mathrm{EC}_{50}\right)$ at which $50 \%$ of DPPH has been removed was expressed as $\mathrm{mg}$ of extract/ $\mu \mathrm{mol}$ of DPPH radical, based on the following equation:

Efficient Concentration $($ EC50) $=$ concentration of test at steady state/concentration of DPPH $t=0$.

The initial DPPH exact concentration $(90.84$ $\mu \mathrm{mol} / \mathrm{L})$ in the reaction system was calculated according to a calibration curve $(\mathrm{Y}=1.145 \mathrm{E}-2 \mathrm{X}-4.192 \mathrm{E}-3 ; \mathrm{r}=0.9999$; where $\mathrm{Y}=$ absorbance and $\mathrm{X}=$ concentration of DPPH) at $514 \mathrm{~nm}$ ). All experiments were performed in triplicate. All spectrophotometric data were obtained using a Thermo Scientific Evolution 60S UV-Visible spectrophotometer. Disposable cuvettes $(1 \mathrm{~cm} \times 1 \mathrm{~cm}$ x $4.5 \mathrm{~cm}$ ) were used for visible absorbance measurements for analyses. BHT standard was used as positive control.

\section{In vitro lipid peroxidation inhibition of methyl linoleate (MeLo)}

A solution of MeLo $10 \mathrm{mM}$ containing $0.02 \%(\mathrm{w} / \mathrm{v})$ of BHT and $0.02 \%(\mathrm{w} / \mathrm{v})$ of each dry extract was exposed to thermal oxidation at $40 \pm 5^{\circ} \mathrm{C}$ for 5 days in test tubes. After accelerated oxidation, each sample was dissolved in $1 \mathrm{~mL}$ of ethanol. The conjugated diene hydroperoxide (CDH) was measured spectrophotometrically at 234 $\mathrm{nm}$. The samples were diluted to 1:25 with ethanol. An extinction coefficient of $29000 / \mathrm{M} \mathrm{cm}$, was utilized to quantify the concentration of $\mathrm{CDH}$ formed during oxidation. The peroxidation level was expressed as mmol $\mathrm{CDH} / \mathrm{kg}$ MeLo (Farhoosh et al., 2012). On the other hand, the level of lipid peroxidation was also expressed as malondialdehyde (MDA) content and was determined as 2-thiobarbituric acid reactive species (TBARS). Briefly, $50 \mu \mathrm{L}$ of sample were mixed with $350 \mu \mathrm{L}$ of ethanol, $100 \mu \mathrm{L}$ BHT $0.2 \% \mathrm{w} / \mathrm{v}$ in ethanol and $500 \mu \mathrm{L}$ of TBA $0.37 \% \mathrm{w} / \mathrm{v}$ in $\mathrm{HCl}(0.25 \mathrm{mM})$ in a test tube. The resulting mixture was heated for $30 \mathrm{~min}$ in a sand bath at $90 \pm 5{ }^{\circ} \mathrm{C}$. After that, the solution was quickly cooled in an ice bath and the flocculated precipitate was removed by centrifugation at $1100 \mathrm{rpm} / 5 \mathrm{~min}$. The absorbance of the samples was measured at $535 \mathrm{~nm}$ and corrected for non-specific turbidity by subtracting the absorbance at $600 \mathrm{~nm}$. MeLo standard was used as positive control. The peroxidation level was expressed as mmol MDA kg-1 MeLo using a molar extinction coefficient of $156000 / \mathrm{M}$ cm (Puertas-Mejía, Ruiz-Díez, Fernández-Pascual, 2010).

\section{UVA-UVB absorption capacity assay}

The UVA-UVB absorption capacity was determined using the absorption coefficient (absorbance DS/mg mL) measured at 290, 310, 340 and $380 \mathrm{~nm}$. Briefly, an aliquot (c.a. $100 \mu \mathrm{L}$ ) of crude extract was added to $2000 \mathrm{~mL}$ of methanol in a quartz cuvette and its absorption spectra (wavelengths 200 - $400 \mathrm{~nm}$ ) was acquired using a Thermo Scientific Evolution 60S UV-Visible spectrophotometer against a blank containing methanol. Benzophenone 3 (B3), butyl methoxydibenzoylmethane (BMDM) and ethylhexyl methoxycinnamate (EHMC) were used as conventional sunscreen standards.

\section{HPLC-DAD-IT-MS ${ }^{\mathrm{n}}$ characterization of the main compounds}

Analysis was performed using an Agilent 1200 series system (Agilent Technology, Palo Alto, CA, USA) equipped with a diode array detector (G1315B), a model G1379B degasser, a binary gradient pump (G1312A), an autosampler G1367B and a column thermostat (G1316A). The analytical column (Waters Symmetry $4.6 \mathrm{~mm}$ x $75 \mathrm{~mm}$ $\mathrm{x} 3.5 \mu \mathrm{m}$ ) was thermostated at $30^{\circ} \mathrm{C}$. The mobile phase consisted of a gradient mixture of (A) $0.1 \%$ formic acid in water and (B) $0.1 \%$ formic acid in methanol. The gradient program was as follows: $30 \% \mathrm{~B}$ (0.5 min), 30-90\% B (6.5 min), 90\% B (1 min), 90-30\% B (1 min), 30\% B (2 min). The phenolic compounds were monitored at 290, 310, 340,380 and $520 \mathrm{~nm}$, and the diode array detector was set to an acquisition range from $190 \mathrm{~nm}$ to $700 \mathrm{~nm}$. The flow rate was $0.5 \mathrm{ml} / \mathrm{min}$, and the injection volume was $2 \mu \mathrm{L}$ (Mejía-Giraldo et al., 2016).

The IT-MS analysis was performed on a Thermo Scientific system equipped with an Accela autosampler 
and an Accela 600 quaternary pump (Thermo Scientific). The mobile phase was composed as described in the analysis of HPLC-DAD, and the injection volume was $10 \mu 1$. The column effluent was analysed by ESI-MS in positive ion mode with an LCQ Fleet Ion Trap (Thermo Scientific). The capillary voltage was set to $35 \mathrm{~V}$, the spray voltage at $4.5 \mathrm{kV}$ and the tube lens offset to $80 \mathrm{~V}$. The sheath gas (nitrogen) flow rate was set to 45 (arbitrary units) and aux gas flow rate to 5 (arbitrary units). The capillary temperature was $300{ }^{\circ} \mathrm{C}$. Data were acquired within $100-1000 \mathrm{~m} / \mathrm{z}$ range. $\mathrm{MS}^{\mathrm{n}}$ experiments were performed in the "Data dependent Ion tree" mode with normalized collision energy of 35 (arbitrary units). For data analysis, the Xcalibur 2.1 (Thermo Scientific) and MZmine 2 (MZmine Development Team) software were used (Pluskal et al., 2010).

\section{Statistical analysis}

Results were expressed as mean \pm standard deviation (at least three replicates). Analysis of variance and significant differences among means and correlation analysis were performed with one-way ANOVA. The experimental data were analysed using SPSS V.21.0 software.

\section{RESULTS AND DISCUSSION}

Certain promising topical treatments for skin aging, including herbal extracts, vitamin and antioxidant supplements, have been widely accepted to scavenge free radicals from skin cells and restore skin elasticity. In this line of work, the search for new natural sources of photoprotective and antioxidant functional compounds has been a challenge. The TPC (expressed in mg GAE/g DS) from selected aerial parts are shown in Table I. The highest concentration of TPC was found in leaf extracts. These results are convenient because leaves are more accessible and easier to collect throughout the year than fruits. On the other hand, the DPPH radical scavenging method is a common practice used for screening the ability of a substance or extract to scavenge free radicals. The $\mathrm{EC}_{50}$ values found were 0.46 and $0.47 \mathrm{~g} / \mu \mathrm{mol} \mathrm{DPPH}$ (fruits and leaves, respectively). According to these findings it is suggested that both leaves and fruit extracts showed strong antiradical capacity and M. parvifolia could be used, e.g. as raw material with application in topical formulations.

Concerning the anthocyanin contents, the results were similar to those obtained with TPC and fluctuated from 1.12 to $1.31 \mathrm{mg} \mathrm{C} 3 \mathrm{GE} / \mathrm{g} \mathrm{DS}$, with the highest content in the leaf extract (Table I). Anthocyanins are particularly abundant in some berries such as blackberry and bilberry (Faria et al., 2010; Garzón et al., 2010). Although, the anthocyanin content in M. parvifolia was too close to that reported for bayberry pomace (Zhou et al., 2009a), in this situation, TAC was higher on leaves than fruits. These results could be linked to some molecular mechanism to reduce the oxidative stress initiated by UV radiation on its organelles and cellular tissue. Therefore, the extracts showed an important scavenging capacity that could be associated with the protection of plants from high altitude against oxidative stress due to UV radiation exposure. Furthermore, the assessment of accelerated oxidation of MeLo on each $M$. parvifolia extract confirmed the antioxidant outcome on the tested substances. Moreover, leaves and fruit extract did not show significant differences $(\mathrm{P}$-value $>0.05)$ with respect to BHT and formation of MDA. In addition, our results were similar to that reported on methanolic extracts of fractions of A. reticulata and Ziziphusjujuba bark species, which showed effective antioxidant

TABLE I - Extraction yield and in vitro antioxidant capacity of $M$. parvifolia (Benth.) Parra-Os

\begin{tabular}{lcccccc}
\hline Extract & Yield \% & $\begin{array}{c}\text { TPC } \\
\text { mg GAE/g DS }\end{array}$ & $\begin{array}{c}\mathbf{E C}_{\mathbf{5 0}} \\
\mathbf{g ~ D S} / \boldsymbol{\mu m o l ~ D P P H}\end{array}$ & $\begin{array}{c}\text { TAC } \\
\mathbf{m g ~ C 3 G E} / \mathbf{g} \text { DS }\end{array}$ & $\begin{array}{c}\text { MDA } \\
\mathbf{m m o l} / \mathbf{k g} \text { MeLo }\end{array}$ & $\begin{array}{c}\text { CDH } \\
\mathbf{m m o l} / \mathbf{~ k g ~ M e L o}\end{array}$ \\
\hline Leaves & $36.79 \pm 0.69^{\mathrm{a}}$ & $51.41 \pm 0.44^{\mathrm{a}}$ & $0.47 \pm 0.01^{\mathrm{a}}$ & $1.31 \pm 0.40^{\mathrm{a}}$ & $0.18 \pm 0.11^{\mathrm{a}}$ & N.D. \\
Fruits & $26.42 \pm 0.41^{\mathrm{b}}$ & $37.58 \pm 0.67^{\mathrm{b}}$ & $0.46 \pm 0.02^{\mathrm{b}}$ & $1.12 \pm 0.41^{\mathrm{a}}$ & $0.10 \pm 0.07^{\mathrm{b}}$ & N.D. \\
MeLo & - & - & - & - & $12.1 \pm 1.9^{\mathrm{a}}$ & $9.2 \pm 2.1^{\mathrm{a}}$ \\
BHT & - & - & $0.112 \pm 0.01$ & - & - & - \\
MeLo+BHT & - & - & - & - & N.D. & N.D. \\
\hline
\end{tabular}

Results are expressed as the mean value \pm standard deviation $(n=3)$. For each parameter, different letters $(\mathrm{a}, \mathrm{b})$ denote significant differences by the LSD test $(\mathrm{P}<0.05)$. TPC (total phenolic content), GAE (gallic acid equivalent), $\mathrm{EC}_{50}$ (efficient concentration at $50 \%$ ), TAC (total anthocyanin content), C3GE (cyanidin-3-O-glucoside equivalents), DS (dry sample), MDA (Malondialdehyde), $\mathrm{CDH}$ (Conjugated diene hydroperoxide), BHT (Butylated hydroxy toluene), MeLo (Methyl linoleate), N.D. (No detected). 
and antiinflammatory properties (Kandimalla et al., 2016a; 2016b). Along these lines, our result showed a satisfactory antioxidant effect of the extracts in the last phase of lipid peroxidation of MeLo.

Plants' phenolic compounds play an important role on human diet for their beneficial health effects, mainly associated with their antioxidant capacity and ability to scavenge free radicals, chelate metal catalysts, activate antioxidant enzymes, etc. The qualitative study in this work, showed the presence of phenols, flavonoids and anthocyanins in both extracts. These outcomes are in good agreement with data reported by some authors (Wollenweber et al., 1985; Santos, Waterman, 2000; Geyid et al., 2005) who have detected the presence of flavonoids in Myricaceae species. According to these results, we found correlation between the yield obtained in both extracts as well as in TPC, TAC content and DPPH analysis. In addition, the $\mathrm{EC}_{50}$ values agree with those reported on methanolic extracts of M. rubra (Myricaceae) (Akazawa et al., 2010). Furthermore, the TPC value obtained was higher than that described for common cultivars, including strawberries (0.844 mg GAE/g) (Kajdžanoska, Petreska, Stefova, 2011) and common legumes (0.57 to $9.60 \mathrm{mg} \mathrm{GAE} / \mathrm{g}$ ) (Xu et al., 2007).

On the other hand, Ion Trap MS analysis delivers better qualitative structural analysis because of its capability to achieve consecutive fragmentation $\left(\mathrm{MS}^{\mathrm{n}}\right)$ with high sensitivity, which is ideal to elucidate the fragmentation pattern. In our case, the HPLC-DAD-IT-MS analysis showed major presence of four components, which were identified as myricetin-3-O-glucoside, myricetin-3-Orhamnoside, rutin and cyanidin-3-O-rutinoside (Table II), and all of them are considered flavonoids that are present in many plants, grapes and cranberries.
Therefore, extracts of $M$. parvifolia showed an interesting UVA-UVB absorption capacity, but both showed a broad-spectrum range similar to the standards (Figure 1). In addition, the absorption coefficients of the extracts were determined and compared at 290, 310, 340 and $380 \mathrm{~nm}$, the selected regions for the UVA and UVB solar spectrum (Figure 2).

The compounds identified showed absorption bands in the UVA and UVB region and the enriched $M$. parvifolia extract could be of great interest as additives in broad-spectrum sunscreen formulations. In addition, an appropriate analysis of phenolic compounds depends on multiple factors such as their chemical nature, sample particle size, storage time, extraction and quantification methods and presence of interferences.

Otherwise, the use of synthetic UV absorbers as sunscreens in commercial cosmetic formulations must offer a broad-spectrum (UVB/UVA) that can be used for different skin pigmentations and environmental conditions, however, these chemical compounds can cause skin irritations. For that reason, screening of natural extracts is a suitable photoprotection strategy to reduce the UV generated ROSmediated skin damage. Although fruits as well as leaves displayed broad-spectrum coverage, it was much higher in the UVB range for the fruit extract. This result has been associated with the presence of phenolic compounds in the extracts that have evidenced absorption of UV radiation (Stevanato, Bertelle, Fabris, 2014). The presence of cyanidin-3-rutinoside and myricetin derivatives possibly increased the ability of both extracts to act as absorbers of UV radiation (Velasco et al., 2008). These phytochemicals have been widely studied due to their anticarcinogenic, antimutagenic, anti-inflammatory and antioxidant actions (Agati, Tattini 2010; Anunciato, da Rocha Filho 2012).

TABLE II - HPLC-DAD-ESI-MS/MS characterization of extracts from M. parvifolia (Benth.) Parra-Os. leaves

\begin{tabular}{|c|c|c|c|c|c|}
\hline Peak & $\mathbf{T}_{\mathrm{R}} \min$ & $\begin{array}{l}\text { UV spectra } \\
\lambda \max (\mathrm{nm})\end{array}$ & {$[\mathbf{M}+\mathbf{H}]^{+}$} & Major $M S^{2}$ and $M^{3} S^{3}$ fragments & Compound* \\
\hline 1 & 4.6 & $257 \mathrm{sh}, 262,298,356$ & 481 & $\begin{array}{l}\mathrm{MS}^{2}: 481 \rightarrow 319,181 \\
\quad \mathrm{MS}^{3}: 319 \rightarrow 181\end{array}$ & Myricetin-3-glucoside \\
\hline 2 & 4.9 & $262,308 \mathrm{sh}, 350$ & 465 & $\begin{array}{c}\mathrm{MS}^{2}: 465 \rightarrow 319 \\
\mathrm{MS}^{3}: 319 \rightarrow 273,245,165\end{array}$ & Myricetin-3-rhamnoside \\
\hline 4 & 7.4 & 520 & 595 & $\begin{array}{c}\mathrm{MS}^{2}: 595 \rightarrow 449,287 \\
\mathrm{MS}^{3}: 449 \rightarrow 287\end{array}$ & Cyanidin-3-rutinoside \\
\hline
\end{tabular}

*Peak compared with standards. 


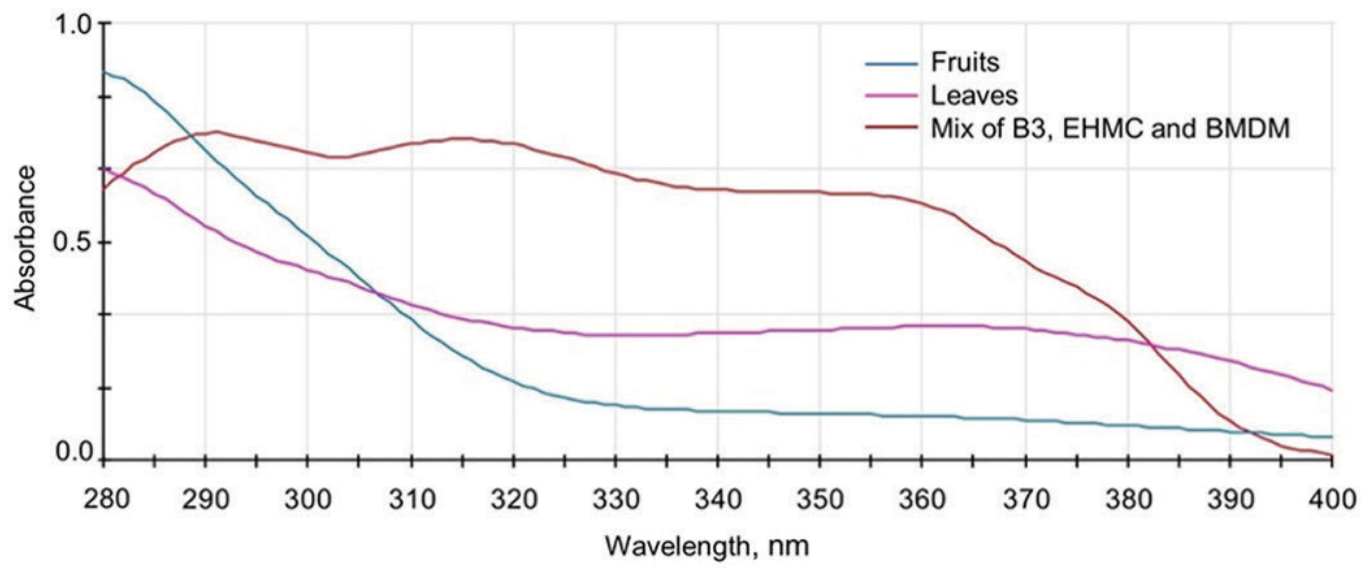

FIGURE 1 - UV spectrum of M. parvifolia extracts (at $0.019 \mathrm{mg} / \mathrm{mL}$, all of them) and a mixed sample of benzophenone 3 (B3), butyl methoxydibenzoylmethane (BMDM), ethylhexyl methoxycinnamate (EHMC) (at $0.017 \mathrm{mg} / \mathrm{mL}$, all of them).

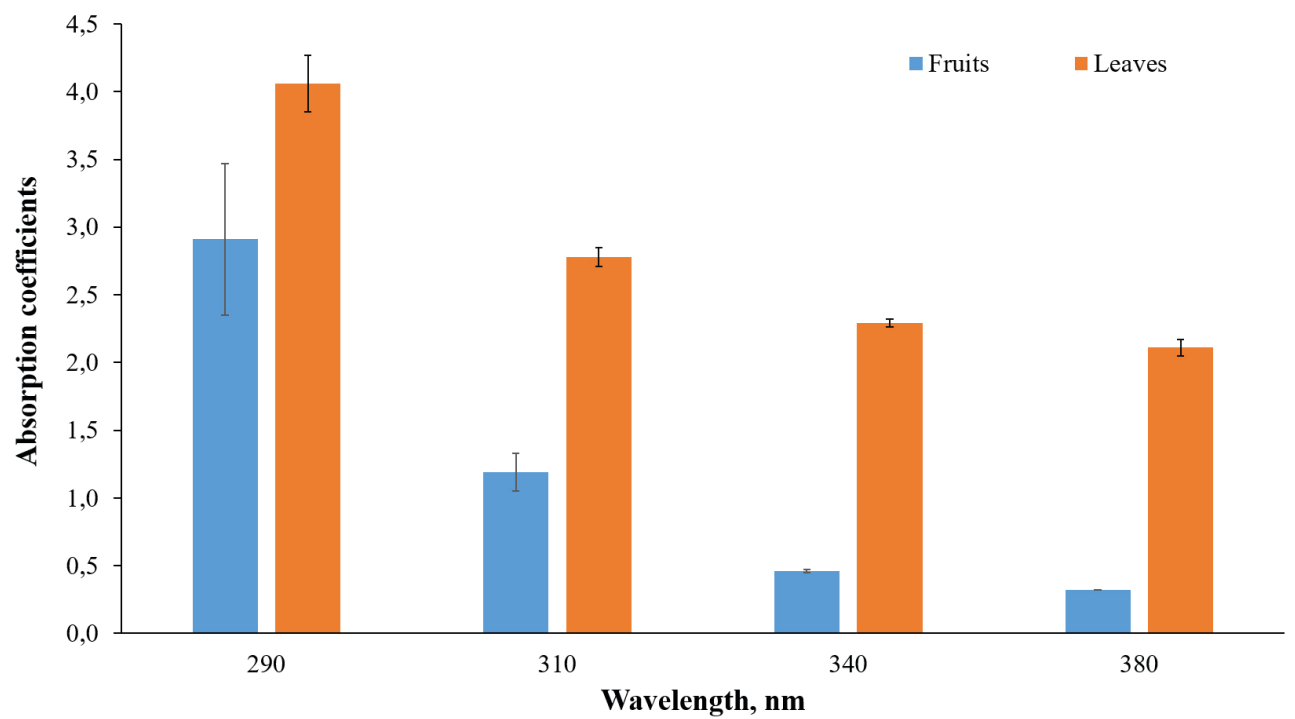

FIGURE 2 - UVA-UVB absorption coefficient (absorbance/ mg DS x mL) at 290, 310, 340 and $380 \mathrm{~nm}$.

\section{CONCLUSIONS}

The photoprotective, phytochemical and antioxidant assays demonstrated that $M$. parvifolia extracts are a prospective source of natural photoprotection and antioxidant substances, then $M$. parvifolia could be evaluated in combination with commercial sunscreens to potentially produce a synergistic effect with promising photoprotection capacity. Furthermore, a deep chemical study of this material must be completed to detect additional compounds that could contribute and enhance these biological properties against the adverse effects of ultraviolet radiation.

\section{ACKNOWLEDGMENTS}

Authors acknowledge University of Antioquia and
CODI (Project no. IN632CE); CONACYT grants I0017/ CB-2010-01/151596; FINNOVA I010/260/2014 and the CINVESTAV Unidad Irapuato, for financial support. J.C. Mejía-Giraldo acknowledges a doctoral fellowship granted by Colciencias (National Research Council). We are grateful to Santiago Varela for his technical assistance.

\section{REFERENCES}

Agati G, Brunetti C, Di Ferdinando M, Ferrini F, Pollastri S, Tattini M. Functional roles of flavonoids in photoprotection: new evidence, lessons from the past. Plant Physiol Biochem. 2013;72:35-45.

Agati G, Tattini M. Multiple functional roles of flavonoids in photoprotection. New Phytol. 2010;186(4):786-93. 
Akazawa H, Fujita Y, Banno N, Watanabe K, Kimura Y, Manosroi A, et al. Three new cyclic diarylheptanoids and other phenolic compounds from the bark of Myrica rubra and their melanogenesis inhibitory and radical scavenging activities. J Oleo Sci. 2010;59(4):213-21.

Anunciato TP, da Rocha Filho PA. Carotenoids and polyphenols in nutricosmetics, nutraceuticals, and cosmeceuticals. J Cosmet Dermatol. 2012;11(1):51-4.

Ashafa AOT. Comparative antimicrobial potential of different extracts and fractions of Morella serrata (Lam.) Killick (Myricaceae). South African J Bot. 2015;98:190.

Bieza K, Lois R. An arabidopsis mutant tolerant to lethal Ultraviolet-B levels shows constitutively elevated accumulation of flavonoids and other pPhenolics. Plant Physiol. 2001;126(3):1105-15.

Brand-Williams W, Cuvelier ME, Berset C. Use of a free radical method to evaluate antioxidant activity. LWT - Food Sci Technol. 1995;28(1):25-30.

Crockett S, Eberhardt M, Kunert O, Schühly W. Hypericum species in the Páramos of Central and South America: a special focus upon H. irazuense Kuntze ex N. Robson. Phytochem Rev. 2010;9(2):255-69.

Damiani E, Rosati L, Castagna R, Carloni P, Greci L. Changes in ultraviolet absorbance and hence in protective efficacy against lipid peroxidation of organic sunscreens after UVA irradiation. J Photochem Photobiol B Biol. 2006;82(3):204-13.

Dohou N, Yamni K, Tahrouch S, Idrissi Hassani LM, Badoc A, Gmira N. Screening phytochimique d'une endémique ibéro-marocaine, Thymelaea lythroides. Bull Soc Pharm Bord. 2003;142(1-4):61-78.

Duraisamy A, Narayanaswamy N, Sebastian A, Balakrishnan PK. Sun protection and anti-inflammatory activities of some medicinal plants. Int J Res Cosmet Sci. 2011;1(1):13-6.

F'guyer S, Afaq F, Mukhtar H. Photochemoprevention of skin cancer by botanical agents. Photodermatol Photoimmunol Photomed. 2003;19(2):56-72.

Farhoosh R, Khodaparast MHH, SharifA, Rafiee SA. Olive oil oxidation: Rejection points in terms of polar, conjugated diene, and carbonyl values. Food Chem. 2012;131(4):1385-90.
Faria A, Pestana D, Teixeira D, de Freitas V, Mateus N, Calhau C. Blueberry anthocyanins and pyruvic acid adducts: anticancer properties in breast cancer cell lines. Phyther Res. 2010;24(12):1862-9.

Garzón GA, Narváez CE, Riedl KM, Schwartz SJ. Chemical composition, anthocyanins, non-anthocyanin phenolics and antioxidant activity of wild bilberry (Vaccinium meridionale Swartz) from Colombia. Food Chem. 2010;122(4):980-6.

Geyid A, Abebe D, Debella A, Makonnen Z, Aberra F, Teka F, et al. Screening of some medicinal plants of Ethiopia for their antimicrobial properties and chemical profiles. J Ethnopharmacol. 2005;97(3):421-7.

Gonzales de la Cruz M, Baldeón Malpartida S, Beltrán Santiago H, Jullian V, Bourdy G. Hot and cold: Medicinal plant uses in Quechua speaking communities in the high Andes (Callejón de Huaylas, Ancash, Perú). J Ethnopharmacol. 2014;155(2):1093-117.

Jarzycka A, Lewińska A, Gancarz R, Wilk KA. Assessment of extracts of Helichrysum arenarium, Crataegus monogyna, Sambucus nigra in photoprotective UVA and UVB; photostability in cosmetic emulsions. J Photochem Photobiol B Biol. 2013;128:50-7.

Kajdžanoska M, Petreska J, Stefova M. Comparison of different extraction solvent mixtures for characterization of phenolic compounds in strawberries. J Agric Food Chem. 2011;59(10):5272-8.

Kandimalla R, Dash S, Kalita S, Choudhury B, Malampati S, Kalita K, et al. Bioactive guided fractions of Annona reticulata L. bark: Protection against liver toxicity and inflammation through inhibiting oxidative stress and proinflammatory cytokines. Front Pharmacol. 2016a;7(Jun):1-12.

Kandimalla R, Dash S, Kalita S, Choudhury B, Malampati S, Kalita K, et al. Protective effect of bioactivity guided fractions of Ziziphus jujuba mill. Root bark against hepatic injury and chronic inflammation via inhibiting inflammatory markers and oxidative stress. Front Pharmacol. 2016b;7(Sep):1-13.

Katiyar SK, Matsui MS, Elmets CA, Mukhtar H. Polyphenolic Antioxidant (-)-Epigallocatechin-3-Gallate from Green Tea Reduces UVB-Induced Inflammatory Responses and Infiltration of Leukocytes in Human Skin. Photochem Photobiol. 1999;69(2):148-53. 
Katiyar SK, Perez A, Mukhtar H. Green Tea Polyphenol Treatment to Human Skin Prevents Formation of Ultraviolet Light B-induced Pyrimidine Dimers in DNA. Clin Cancer Res. 2000;6(10):3864-9.

Lee J, Durst RW, Wrolstad RE. Determination of total monomeric anthocyanin pigment content of fruit juices, beverages, natural colorants, and wines by the $\mathrm{pH}$ differential method: collaborative study. J AOAC Int. 2005;88(5):1269-78.

Mejía-Giraldo JC, Winkler R, Gallardo C, Sánchez-Zapata AM, Puertas-Mejía MA. Photoprotective Potential of Baccharis antioquensis (Asteraceae) as Natural Sunscreen. Photochem Photobiol. 2016;92(5):742-52.

Mellegård H, Stalheim T, Hormazabal V, Granum PE, Hardy SP. Antibacterial activity of sphagnum acid and other phenolic compounds found in Sphagnum papillosum against food-borne bacteria. Lett Appl Microbiol. 2009;49(1):85-90.

Morales LO, Tegelberg R, Brosché M, Lindfors A, Siipola S, Aphalo PJ. Temporal variation in epidermal flavonoids due to altered solar UV radiation is moderated by the leaf position in Betula pendula. Physiol Plant. 2011;143(3):261-70.

Parra C. Revisión taxonómica de la familia Myricaceae en Colombia. Caldasia. 2003;25(1):23-64.

Pereira MP, Tavano OL. Use of different spices as potential natural antioxidant additives on cooked beans (Phaseolus vulgaris). Increase of DPPH radical scavenging activity and total phenolic content. Plant Foods Hum Nutr. 2014;69(4):337-43.

Pérez-Sánchez A, Barrajón-Catalán E, Caturla N, Castillo J, Benavente-García O, Alcaraz M, et al. Protective effects of citrus and rosemary extracts on UV-induced damage in skin cell model and human volunteers. J Photochem Photobiol B. 2014;136:12-8.

Pluskal T, Castillo S, Villar-Briones A, Orešič M. MZmine 2: Modular framework for processing, visualizing, and analyzing mass spectrometry-based molecular profile data. BMC Bioinformatics. 2010;11(1):395.

Ponzo OJ, Silvia C. Evidence of reproductive disruption associated with neuroendocrine changes induced by UV-B filters, phthalates and nonylphenol during sexual maturation in rats of both gender. Toxicology. 2013;311(1-2):41-51.
Puertas-Mejía MA, Ruiz-Díez B, Fernández-Pascual M. Effect of cadmium ion excess over cell structure and functioning of Zea mays and Hordeum vulgare. Biochem Syst Ecol. 2010;38(3):285-91.

Santos SC, Waterman PG. Condensed tannins from Myrica gale. Fitoterapia. 2000;71(5):610-2.

Stahl W, Heinrich U, Jungmann H, Sies H, Tronnier H. Carotenoids and carotenoids plus vitamin E protect against ultraviolet light-induced erythema in humans. Am J Clin Nutr. 2000;71(3):795-8.

Stevanato R, Bertelle M, Fabris S. Photoprotective characteristics of natural antioxidant polyphenols. Regul Toxicol Pharmacol. 2014;69(1):71-7.

Svobodová A, Psotová J, Walterová D. Natural phenolics in the prevention of UV-induced skin damage. A review. Biomed Pap. 2003;147(2):137-45.

Sylvestre M, Legault J, Dufour D, Pichette A. Chemical composition and anticancer activity of leaf essential oil of Myrica gale L. Phytomedicine. 2005;12(4):299-304.

Velasco MVR, Sarruf FD, Salgado-Santos IMN, HaroutiounianFilho CA, Kaneko TM, Baby AR. Broad spectrum bioactive sunscreens. Int J Pharm. 2008;363(1-2):50-7.

Wollenweber E, Kohorst G, Mann K, Bell JM. Leaf Gland Flavonoids in Comptonia peregrina and Myrica pensylvanica (Myricaceae). J Plant Physiol. 1985;117(5):423-30.

Xu BJ, Yuan SH, Chang SKC. Comparative analyses of phenolic composition, antioxidant capacity, and color of cool season legumes and other selected food legumes. J Food Sci. 2007;72(2):S167-77.

Zhou S, Fang Z, Lü Y, Chen J, Liu D, Ye X. Phenolics and antioxidant properties of bayberry (Myrica rubra Sieb. et Zucc.) pomace. Food Chem. 2009a;112(2):394-9.

Zhou Y-H, Zhang Y-Y, Zhao X, Yu H-J, Shi K, Yu J-Q. Impact of light variation on development of photoprotection, antioxidants, and nutritional value in lactuca sativa L. J Agric Food Chem. 2009b;57(12):5494-500.

Received for publication on $17^{\text {th }}$ August 2017 Accepted for publication on $19^{\text {th }}$ January 2018 